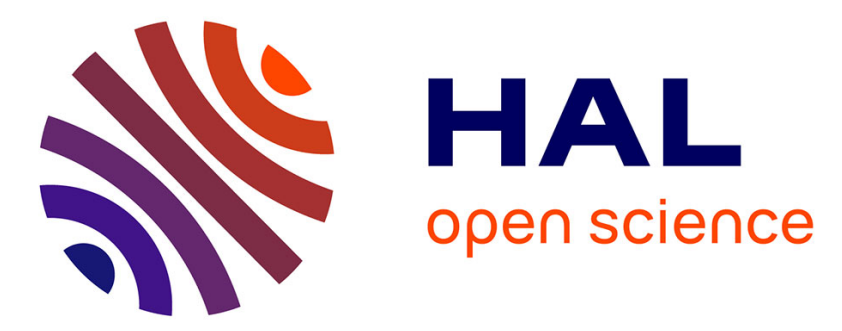

\title{
Experimental and numerical analysis of corrosion-induced cover cracking in reinforced concrete sample
}

Benjamin Richard, Marc Quiertant, Veronique Bouteiller, Arnaud Delaplace, Lucas Adelaide, Frédéric Ragueneau, Christian Cremona

\section{To cite this version:}

Benjamin Richard, Marc Quiertant, Veronique Bouteiller, Arnaud Delaplace, Lucas Adelaide, et al.. Experimental and numerical analysis of corrosion-induced cover cracking in reinforced concrete sample. Computers and Concrete, an International Journal, 2016, 18 (3), pp.421-439. 10.12989/cac.2016.18.3.421 . hal-01500827

\section{HAL Id: hal-01500827 \\ https://hal.science/hal-01500827}

Submitted on 3 Apr 2017

HAL is a multi-disciplinary open access archive for the deposit and dissemination of scientific research documents, whether they are published or not. The documents may come from teaching and research institutions in France or abroad, or from public or private research centers.
L'archive ouverte pluridisciplinaire HAL, est destinée au dépôt et à la diffusion de documents scientifiques de niveau recherche, publiés ou non, émanant des établissements d'enseignement et de recherche français ou étrangers, des laboratoires publics ou privés. 


\title{
Experimental and numerical analysis of corrosion-induced cover cracking in reinforced concrete sample
}

\author{
Benjamin Richard ${ }^{1}$, Marc Quiertant ${ }^{2}$, Véronique Bouteiller ${ }^{2}$, Arnaud Delaplace ${ }^{3}$, \\ Lucas Adelaide $^{* 2}$, Frédéric Ragueneau ${ }^{4}$ and Christian Cremona ${ }^{5}$ \\ ${ }^{1} C E A, D E N$, DANS, DM2S, SEMT, Laboratoire d'Etudes Mécaniques et Sismiques \\ F-91191 Gif sur Yvette, France \\ ${ }^{2}$ Université Paris-Est, IFSTTAR, Département Matériaux et structures, \\ 14-20 boulevard Newton, 77447 Marne-la-Vallée Cedex 2, France \\ ${ }^{3}$ Lafarge Centre de Recherche - Mécanique et Modes Constructifs, \\ 95 Rue du Montmurier, 38291 Saint Quentin Fallavier, France \\ ${ }^{4}$ LMT/ENS Cachan/CNRS/Univ. Paris 6/PRES UniverSud \\ 61 Avenue du President Wilson, 94230 Cachan, France \\ ${ }^{5}$ Bouygues Construction, Guyancourt, Île-de-France, France.
}

\begin{abstract}
Corrosion of embedded reinforcing bars is recognized as being the major cause of deterioration of reinforced concrete structures. With regard to maintenance strategies of concrete nuclear structures, the monitoring of cracking remains of primary importance. Recently, authors have developed a post-treatment technique to extract crack features from continuous computations. In this paper, such technique is applied to carry out a numerical analysis of an accelerated corrosion test. Obtained results allow highlighting specific propagation and failure mechanisms that characterize corrosion-induced cracking.
\end{abstract}

Keywords: discrete elements; finite elements; damage mechanics; multi-scale modelling; corrosion

\section{Introduction}

Corrosion of steel reinforcement has been identified as being one of the major causes of reinforced concrete (RC) structures deterioration (Broomfield 1997, Bentur and Berke 1998). Both the serviceability and the durability of RC structures may be drastically affected by reinforcing-bar (rebar) corrosion. At a first stage of the corrosion process (Tilly and Jacobs 2007, Bertolini et al. 2004), the bond properties between steel and concrete decrease. Then, the swelling nature of the corrosion products creates an expansive pressure at the interface between steel and the surrounding concrete. This could lead to the development of cracking and sometimes to the concrete cover spalling (Mehta et al. 2006). Simultaneously, the effective cross-section area of the steel reinforcement decreases, leading to a loss of load carrying capacity, stiffness and finally service life of the structure. Due to such detrimental effect of corrosion, it is a major concern to develop 
predictive models to assess the corrosion level of a RC structure before the whole concrete cover becomes fully cracked. Considering that appearance and width of corrosion-induced cracks on the surface of a RC structure are indicators of the corrosion state, it can be concluded that an accurate understanding of the concrete cover damage process could help stakeholders defining an efficient maintenance policy (Care et al. 2010, Andrade et al. 1993, Matthews et al. 2007).

In view of the aforementioned discussion, it appears necessary to show how recent numerical techniques can help predicting the effects of corrosion as well as to better understand the complex mechanisms related to concrete cover cracking. Based on the results of an accelerated corrosion test, a numerical study of corrosion-induced cracking is exposed in this paper with the aim of analyzing local failure mechanisms when corrosion is propagating.

Recent studies clearly show that civil engineers are more familiar with continuous approaches like smeared crack approach (Rots 1991, Jirasek and Zimmermann 1998, Jirasek and Zimmermann 2001a, b), continuum damage mechanics (Dragon and Mroz 1979, La Borderie et al. 1993, Fremond and Nedjar 1995, Ragueneau et al. 2000, Ragueneau et al. 2006, Mazars 1989) and plasticity (Jason et al. 2006, Grassl and Jirasek 2006) to deal with concrete cracking than with discontinuous ones like strong discontinuity method (Oliver 1996) or extended finite element (FE) method (Moes et al. 1999, Belytschko and Black 1999). Therefore, the authors have chosen to study corrosion-induced cracking with a two-level method (Richard et al. 2010a). First, computation with an isotropic continuum damage mechanics based model is carried out to provide a global displacement field solution. Due to its continuous nature, an estimation of crack width is not straightforward. Indeed, the discrete nature of cracking phenomenon is not taken into account by continuous approaches. From the resulting damage pattern, some regions of interest (ROI) can be identified. Second, these critical regions are studied thanks to a discrete element (DE) model (Delaplace and Ibrahimbegovic 2006). The boundary conditions lie in considering the displacement field coming from the continuous computation and in projecting it on the non-free surfaces of the critical regions. The discrete analysis is fully uncoupled from the continuous one, making it possible to be used with any satisfactory continuous model.

To expose the results of this study, this paper is outlined as follows. In section 2, the numerical approach is presented. The FE model is discussed as well as the DE one. The coupling strategy is then presented. In section 3, the results coming from the experimental analysis of the RC sample are exposed. In the last section, the combining DE/FE approach is used to analyze the experimental measurements, leading to draw some conclusions about the local failure mechanisms related to corrosion-induced cracking.

\section{Post-treatment technique for fine crack description}

\subsection{General framework}

Although continuous approaches are largely used when dealing with nonlinear problems, they fail to predict local information such as crack widths. In this study, a post-treatment technique to extract crack features from continuous computations is used. In fact, it is shown that this type of technique can help civil engineers dealing with structures exhibiting cracking issues.

The post-treatment technique is based on the combined use of FE and DE methods. The main idea is first to carry out a continuous computation with a satisfactory continuous model. From the displacement field solution, ROI can be identified. The ROI are parts of the whole material domain 


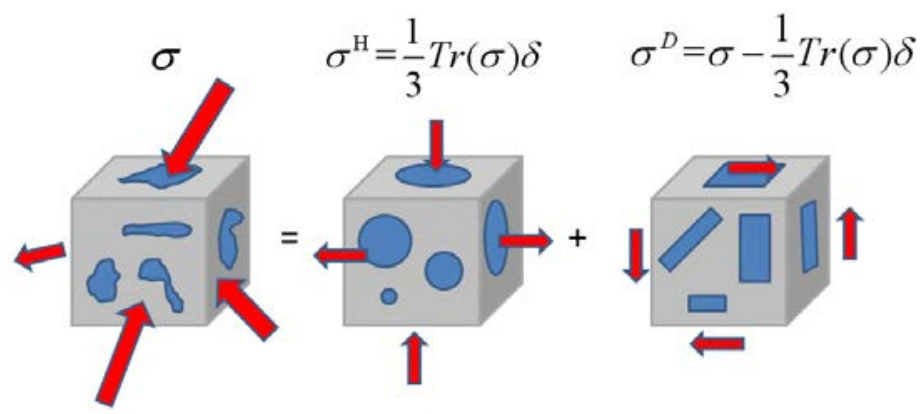

Fig. 1 Decomposition of cracked medium into hydrostatic (width and closing) and deviatoric (frictional sliding) effects

where cracking (strain localization) is developing. Second, only in the ROI, fine computations are performed thanks to a discrete model, ensuring that crack features can be captured. The boundary conditions related to the discrete analysis come from the continuous displacement field.

More precisely, the continuous displacements field is interpolated along the non-free surfaces of the ROI that have been meshed by mean of DEs. This way of transferring information from the continuous model to the discrete one ensures (i) the post-treatment technique to be non-intrusive and (ii) to be used with any continuous/discrete model since their ability to describe nonlinear phenomena and cracking has been shown. The main steps of this combining analysis are the following ones

1. continuous computation,

2. identification of the ROI,

3. projection and interpolation of the continuous displacement field solution,

4. discrete computation.

\subsection{Continuous model}

\subsubsection{Thermodynamic framework}

This section is devoted to the formulation of a constitutive model for concrete.

Formulating a constitutive model within the rigorous and consistent framework of the irreversible processes thermodynamics (Lemaitre et al. 1985) requires the definition of a state potential. This functional must be positive, convex and differentiable with respect to each state variable. Moreover, this potential must lead to a meaningful description of local mechanisms involved in the failure process of concrete such as the strong dissymmetry between the behaviours in tension and in compression, the inelastic strains (in tension as well as in compression) and the unilateral effect (Mazars et al. 1990).

To split the difficulties, the cracked behaviour will be assumed to be separated into two independent behaviours (Pensée et al. 2002): the hydrostatic part and the deviatoric part. Crack width and closing are considered on the hydrostatic part and the frictional sliding is considered on the deviatoric part. These assumptions are illustrated in Fig. 1.

This choice leads to a decomposition of the strain energy into two different parts: the hydrostatic and the deviatoric components. This feature is one of the key points to fully take damage and sliding into account. Therefore, the considered thermodynamic state potential is chosen in the following form (Richard et al. 2010b) 


$$
\begin{aligned}
\rho \Psi= & \frac{\kappa}{6}\left((1-d)<\varepsilon_{k k}>_{+}^{2}-<-\varepsilon_{k k}>_{+}^{2}\right)+(1-d) \mu \varepsilon_{i j}^{d} \varepsilon_{i j}^{d}+d \mu\left(\varepsilon_{i j}^{d}-\varepsilon_{i j}^{\pi}\right)\left(\varepsilon_{i j}^{d}-\varepsilon_{i j}^{\pi}\right) \\
& +\frac{\gamma}{2} \alpha_{i j} \alpha_{i j}+H(z)
\end{aligned}
$$

where $\rho$ is the material density, $\Psi$ the Helmholtz free energy, $d$ the scalar damage variable ranging from 0 (virgin material) to 1 (fully broken material), $\varepsilon_{i j}$ the total strains second-order tensor, $\varepsilon_{i j}^{\pi}$ the internal sliding second-order tensor, $\alpha_{i j}$ the kinematic hardening second-order tensor, $z$ the scalar isotropic hardening variable, $H$ the consolidation function, $\kappa$ the bulk coefficient, $\mu$ the shear modulus and $\gamma$ the kinematic hardening parameter that has to be identified from measurements. \langle\rangle$_{+}$and <.> stand for the positive part and the negative part of (.) respectively. (.) ${ }^{d}$ is the deviatoric part of (.) and is defined by $(.)_{i j}^{d}=(.)_{i j}-\frac{1}{3}(.)_{k k} \delta_{i j}$. One can notice that the mathematical requirements related to the state potential are fulfilled (Adelaide et al. 2010).

The corresponding state laws can be derived from Eq. (1).

$$
\sigma_{i j}=\rho \frac{\partial \Psi}{\partial \varepsilon_{i j}}=\frac{\kappa}{3}\left((1-d)<\varepsilon_{k k}>_{+}+<\varepsilon_{k k}>_{-}\right) \delta_{i j}+2(1-d) \mu \varepsilon_{i j}^{d}+2 d \mu\left(\varepsilon_{i j}^{d}-\varepsilon_{i j}^{\pi}\right)
$$

where $\delta_{i j}$ is the Kronecker's tensor. The unilateral effect is taken into account thanks to an appropriate state coupling between the damage variable $d$ and the hydrostatic part of the Helmholtz free energy. The variable $d$ acts only on the positive part related to the hydrostatic part of the state potential.

Nevertheless, due to the scalar nature of the damage variable, the crack closure effect is only partially considered. The hysteretic effect is included in the model through the internal sliding tensor that is coupled with the damage variable to introduce the fact that sliding will not appear when cracks are closed (damage variable is equal to 0 ). The frictional stress second-order tensor can be defined according to

$$
\sigma_{i j}^{\pi}=-\rho \frac{\partial \Psi}{\partial \varepsilon_{i j}^{\pi}}=2 d \mu\left(\varepsilon_{i j}^{d}-\varepsilon_{i j}^{\pi}\right)
$$

One can notice that $\sigma_{i j}^{\pi}$ is a pure deviatoric tensor. Therefore, the flow rules must be properly defined in order to ensure that $\varepsilon_{i j}^{\pi}$ is also purely deviatoric. On the other hand, the state coupling between the damage and the internal sliding variables will allow modeling the non linear variation of the hysteretic effect. In fact, in the case of cyclic loadings, hysteretic loops will be function of the damage intensity. The energy rate released due to damage is defined such as

$$
Y=-\frac{\partial \rho \Psi}{\partial d}=\frac{\kappa}{6}<\varepsilon_{k k}>_{+}^{2}+\frac{\mu}{2} \varepsilon_{i j}^{d} \varepsilon_{i j}^{d}-\mu\left(\varepsilon_{i j}^{d}-\varepsilon_{i j}^{\pi}\right)\left(\varepsilon_{i j}^{d}-\varepsilon_{i j}^{\pi}\right)=Y_{N}^{+}+Y_{d}-Y_{\pi}
$$

where $Y_{N}^{+}=\frac{\kappa}{6}<\varepsilon_{k k}>_{+}^{2}$ is the part of the energy rate released due to damage related to mode I 
(width), $Y_{d}=\mu \varepsilon_{i j}^{d} \varepsilon_{i j}^{d}$ the part related to mode II (shearing) and $Y_{\pi}=\mu\left(\varepsilon_{i j}^{d}-\varepsilon_{i j}^{\pi}\right)\left(\varepsilon_{i j}^{d}-\varepsilon_{i j}^{\pi}\right)$ the part related to internal sliding. The back stress second-order tensor can be determined by differentiating Eq. (1) with respect to the kinematic hardening variable.

$$
X_{i j}=\frac{\partial \rho \Psi}{\partial \alpha_{i j}}=\gamma \alpha_{i j}
$$

Last, the thermodynamic force $Z$ related to the isotropic hardening is expressed as a function of the consolidation function $H$

$$
Z=\frac{\partial \rho \Psi}{\partial z}=\frac{d H(z)}{d z}
$$

Complementary equations are needed to drive the irreversible part of the behaviour. The damage mechanism and the isotropic hardening flow according to an associative law. This helps to define a unique threshold surface and therefore a unique Lagrange multiplier that makes the numerical implementation of the model not only easier but also more robust. The internal sliding and the kinematic hardening flow according to a non-associative law to ensure an appropriate description of the nonlinear nature of the hysteretic effects. The permanent strain and frictional sliding effects are taken into account by considering a suitable pseudo potential of dissipation, as the one proposed in (Armstrong and Frederick 1966). The numerical implementation of this constitutive law as well as a discussion about its ability to deal with large-scale structures can be found in (Richard et al. 2010b).

\subsubsection{Regularization}

The regularization of the problem is ensured thanks to the well-known non local technique (Pijaudier-Cabot and Bazant, 1987). It lies in averaging the energy rate released due to damage $\bar{Y}(x)$ in a certain vicinity $\Omega\left(x, l_{c}\right)$ related to each material point, where $x$ and $l_{c}$ stand for the current Gauss point and the characteristic length respectively. The averaged energy rate $\tilde{Y}(x)$ is expressed according to

$$
\tilde{Y}(x)==\frac{\int_{\Omega\left(x, l_{c}\right)} \bar{Y}(s) \Lambda(x-s) d s}{\int_{\Omega\left(x, l_{c}\right)} \Lambda(x-s) d s}
$$

where $\Lambda$ is the Gaussian function. To ensure that the model is regularized, it is sufficient to replace the local energy rate $\bar{Y}(x)$ by the averaged one $\tilde{Y}(x)$. The corresponding characteristic length $l_{c}$ can be chosen such as 2 or $3 \mathrm{FE}$ are included in the vicinity $\Omega\left(x, l_{c}\right)$.

\subsection{Discrete model}

A particle-based discrete model is used for the fine crack description. With this approach, the material is described as a particle assembly. A crack is naturally obtained if a bond linking two 
particles breaks. A Voronoi tessellation is used, allowing an efficient and easy mesh generation. The particle nuclei are randomly generated on a grid (Moukarzel and Herrmann 1992) in order to control the boundary conditions.

Cohesion forces can be equally represented either by springs at the interface of neighboured particles or by beams linking the nuclei of the particles. Euler-Bernoulli beams are chosen in the model used in this study. Then, four parameters of the beams have to be identified: the length $\ell_{b}$, the cross-sectional area $A_{b}$, the inertia $I_{b}$ (or the adimensional parameter $\alpha=I_{b} / I_{0}$ where $I_{0}$ is the inertia of the equivalent circular section of the beams linking two discrete particles) and the elastic modulus $E_{b}$ of the beam (Schlangen and Garbozci 1997, Van Mier et al. 2002). The first two parameters are imposed by the mesh geometry. The two last parameters are identified in order to obtain the elastic properties of the material, $E$ and $v$, respectively the Young's modulus and the Poisson's ratio (Delaplace and Desmorat 2007). It is important to note that if necessary, it is possible to compute contact forces between unlinked particles, for example for cyclic loading with crack widths and closing.

The nonlinear behaviour of the material is obtained by assuming a brittle behaviour of the beams. Such simple assumption is available because the model represents the material at a mesoscale, where just a simple phenomenon, a crack width in mode I, is represented. The failure threshold $P_{i j}$ depends not only on the beam strain but also on the rotations of the particles (respectively $i$ and $j$ ) linked by the beam. This leads to

$$
P_{i j}=\left(\frac{\varepsilon_{i j}}{\varepsilon_{i j}^{c r}}\right)^{2}+\frac{\left|\theta_{i}-\theta_{j}\right|}{\theta_{i j}^{c r}}>1
$$

where $\varepsilon_{i j}$ is the strain in the beam linking the particles $i$ and $j, \theta_{i}$ and $\theta_{j}$ are the rotation angles of both extremities of the beam. The critical strain $\varepsilon_{i j}^{c r}$ and the critical rotation $\theta_{i j}^{c r}$ of the beam $i-j$ are picked from a random number generator according to the Weibull distribution (Van Mier et al. 2002). This feature allows taking into account the random and heterogeneous nature of concrete. Note that if the threshold depends only on the beam strain, the compressive strength is overestimated by the model. With this simple beam model, one can obtain a reliable description of the material behaviour, either for uniaxial loadings or biaxial ones (Delaplace 2009).

The crack pattern is defined as the common side of the particles initially linked by the breaking beams. The width of the crack is computed by considering the relative displacement $\left(\boldsymbol{u}_{i}-\boldsymbol{u}_{j}\right)$ of the unlinked particles $i$ and $j$. This approximation can be justified by the fact that particles are supposed to be rigid bodies and the material close to the crack lips is unloaded. The measure of the width between two particles $i$ and $j$ is projected on the normal $n_{i j}$ of the local discontinuity and is expressed as

$$
e_{i j}=<\left(\boldsymbol{u}_{i}-\boldsymbol{u}_{j}\right) \cdot n_{i j}>_{+}
$$

where the dot stands for the $\mathbf{R}^{2}$ or $\mathbf{R}^{3}$ inner product, depending on the dimension of the problem.

\subsection{Combining strategy}

The combining strategy between the continuous computation and the discrete model is made thanks to an appropriate transfer of boundary conditions (Richard et al. 2010a, Oliver et al. 2013). 
The displacement field resulting from the continuous analysis is projected on the non-free surfaces
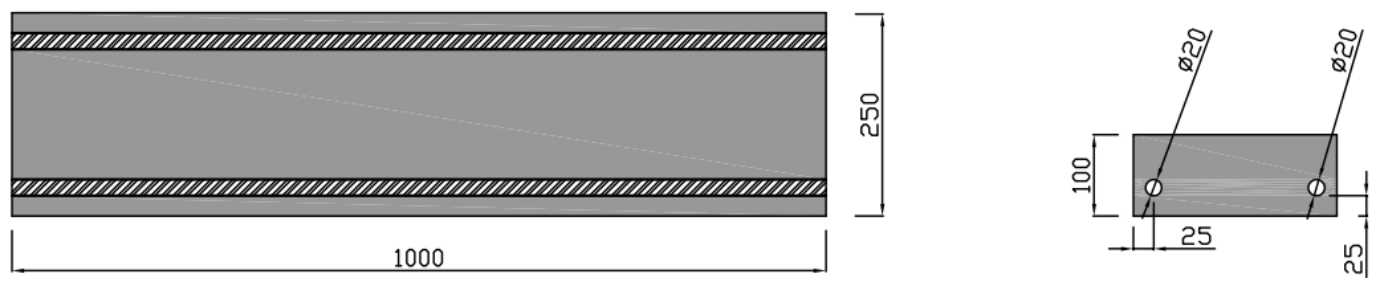

Fig. 2 Geometry of the RC specimen (all dimensions are in $\mathrm{mm}$ )

of the ROI that has been modelled thanks to the discrete approach. To interpolate the displacement from the continuous mesh to the discrete one, the most natural way lies in using the FE shape functions. Considering the coordinates $x_{d}$ of a given nuclei, the corresponding displacement $\boldsymbol{u}\left(x_{d}\right)$ is expressed as

$$
\boldsymbol{u}\left(x_{d}\right)=\sum_{i=1}^{n n} N_{i}\left(x_{d}\right) \boldsymbol{u}_{i}
$$

where $n n$ is the number of nodes, $N_{i}$ is the shape function related to the node $i$ and $u_{i}$ is the vector of nodal displacements coming from the continuous computation.

\section{Accelerated corrosion test}

\subsection{Description of the specimen}

The test specimen is a $1000 \mathrm{~mm}$ long RC beam with a $250 \times 100 \mathrm{~mm}^{2}$ rectangular cross section reinforced longitudinally with two $20 \mathrm{~mm}$ diameter steel deformed rebars. The concrete cover thickness is $25 \mathrm{~mm}$. A schematic representation of the RC specimen is given in Fig. 2.

The beam is not mechanically loaded. The cement type used is standard CEMI 52.5 PMES CP2 $\mathrm{NF}$ with a weight density equal to $340 \mathrm{~kg}$ per cubic meter of concrete. The sand as well as the aggregates type is Bernière 0/4 and 6.3/20 respectively. The related weight densities are $739.45 \mathrm{~kg}$ and $1072.14 \mathrm{~kg}$ per cubic meter of concrete. Water has been added to the mixture with a weight density equal to $184.22 \mathrm{~kg}$ per cubic meter of concrete. The water/cement ratio is $\frac{\omega}{c}=0.54$. Material characteristics of concrete have been identified on 28-day aged cylinders (160 mm in diameter, $320 \mathrm{~mm}$ long). Compressive and tensile strength were measured according to standards NF EN 12390-3 (AFNOR 2003) and NF EN 12390-6 (AFNOR 2001). The mean compressive strength is $44.7 \mathrm{MPa}$, the mean tensile strength is $3.3 \mathrm{MPa}$ and the Young's modulus is 36500 $\mathrm{MPa}$. The Poisson's ratio has not been measured, its value is assumed to be equal to 0.2.

\subsection{Description of the accelerated corrosion set-up}

The accelerated corrosion test that is presented in Fig. 3, is adapted from the one proposed in (Care et al. 2010, Nguyen et al. 2007). The main features about the experimental set-up are given in this 
section and more details can be found in the literature (Richard et al. 2012).

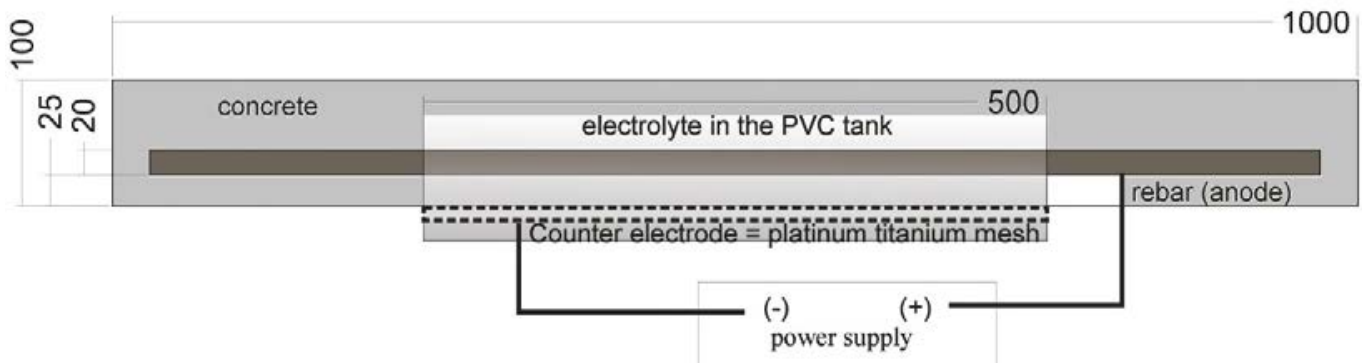

Fig. 3 Scheme of the accelerated corrosion setup; the corroded area is located in the centre of the reinforced concrete sample

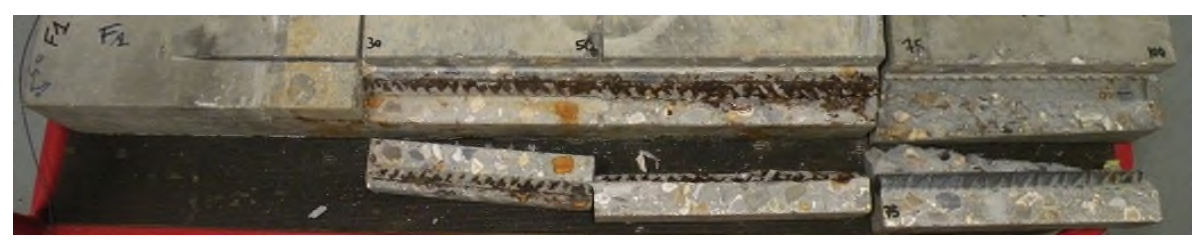

Fig. 4 Post-mortem analysis of the RC sample where corroded and non corroded areas can be observed

The accelerated corrosion test deals with placing the central part (500 mm length) of the RC sample in a PVC tank containing an alkaline salted solution $\left(1 \mathrm{~g} \mathrm{~L}^{-1} \mathrm{NaOH}+4.65 \mathrm{~g} \mathrm{~L}^{-1} \mathrm{KOH}+30\right.$ $\left.\mathrm{g} \mathrm{L}^{-1} \mathrm{NaCl}\right)$, and polarizing the two rebars anodically. The counter electrode made of a titanium platinum mesh (500 mm long, $250 \mathrm{~mm}$ wide) was placed at the bottom of the beam. The central part of the beam was immersed in the saline solution one day before putting on the anodic corrosion. A power supply was used for applying a constant, direct current $\left(100 \mu \mathrm{A} \mathrm{cm}^{-2}\right.$ of the surface of the steel cross-section) between the reinforcement and the counter electrode. The thirty days (700 cumulated hours) duration of the accelerated corrosion was chosen according to preliminary corrosion tests performed on similar specimens. This accelerated corrosion set-up led to localize the corrosion process only in the central part of the RC sample as can be observed in Fig. 4.

Assuming uniform corrosion on the rebar surface, the corrosion-induced radius loss of steel $\Delta r(m)$ can be estimated according to the Faraday's equation (Care and Raharinaivo 2007, Nguyen et al. 2007)

$$
\Delta r=\frac{M j t}{\rho z F}
$$

where $M$ is the iron molar weight $\left(55.85 \mathrm{~g} \mathrm{~mol}^{-1}\right), \rho$ the iron weight density $\left(7.800 \mathrm{Mg} \mathrm{m}^{-3}\right), j$ the chosen current density $\left(\mathrm{A} \mathrm{m}^{-2}\right), z$ the valence number (equal to 2$), F$ the Faraday's constant $(96500$ $\mathrm{C} \mathrm{mol}^{-1}$ ) and $t$ the time (s). By applying Eq. (11), one obtains $\Delta r(m)=96 \mu \mathrm{m}$.

Comparing this theoretical value to the one observed in post-mortem analysis leads to a relative error of less than $10 \%$.

The question of representativeness when performing accelerated tests can be pointed out. The 
authors would like to mention that the test that has been carried out aims at providing sufficient

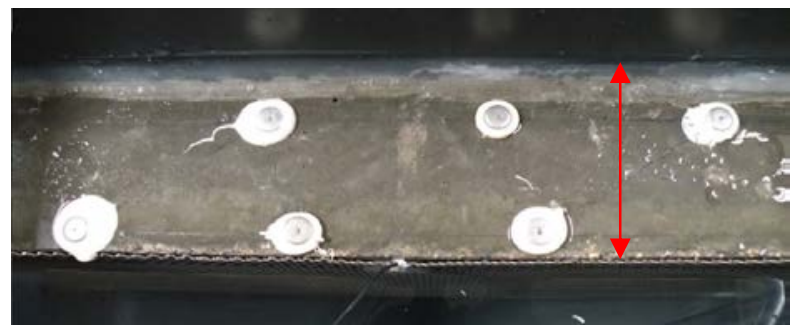

Fig. 5 Location of pins for measurement

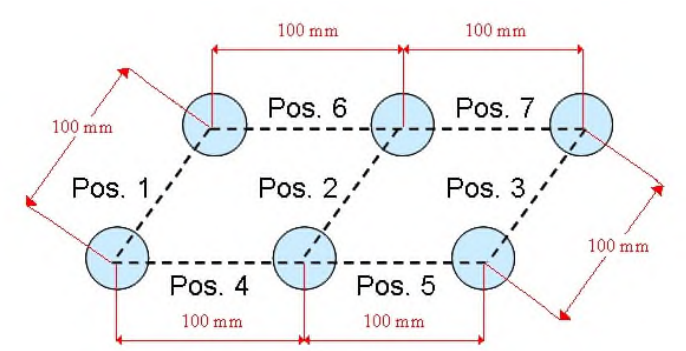

Fig. 6 Pins positioning and resulting 7 positions of the measurements

material to help understanding corrosion-induced cracking phenomenon better. If experimental data involving cracking due to long-term atmospheric corrosion and clear results about quantitative information had been available in the literature, they could also have been used to reach the aforementioned objective. Unfortunately, no such study is available in the literature according to the authors' knowledge.

\subsection{Cracking measurements}

Crack width measurements were periodically performed using a PFENDER extensometer (ballextensometer). First of all, six pins were stuck on the studied face of the beam, as depicted in Fig. 5 .

Pins are oriented by pair according to a given generating line. The initial distance between two pins of the same pair is set to about $100 \mathrm{~mm}$. This distance is imposed by the extensometer. To limit initial measurement uncertainties, each measure of spacing results of the subtraction of the effective pins spacing and the measurement of a $100 \mathrm{~mm}$ invar gauge. The difference between the measure at a given time $\left(t \neq t_{0}\right)$ and the initial one $\left(t=t_{0}\right)$ characterizes the expansion along the generating line. The energy released into the glue is assumed to be equal to zero. Therefore, the measured expansions are assumed to be only due to the concrete deformation process or crack width evolution. It must be underlined that when a crack appears between two pins, the crack mouth width displacement is assumed to be equal to the pins spacing evolution (i.e. concrete strain outside the crack is neglected). Due to the limited height of the concrete beam $(100 \mathrm{~mm})$, the imposed value of the spacing between two pins of the same pair make it impossible to position the upper horizontal layer of pins perpendicular to the first layer. Consequently, a parallelogramic scheme is used for pins positioning (see Fig. 5). The different possibilities of measurements are 
presented in Fig. 6. In this paper, positive strain values correspond to tensile strains and negative

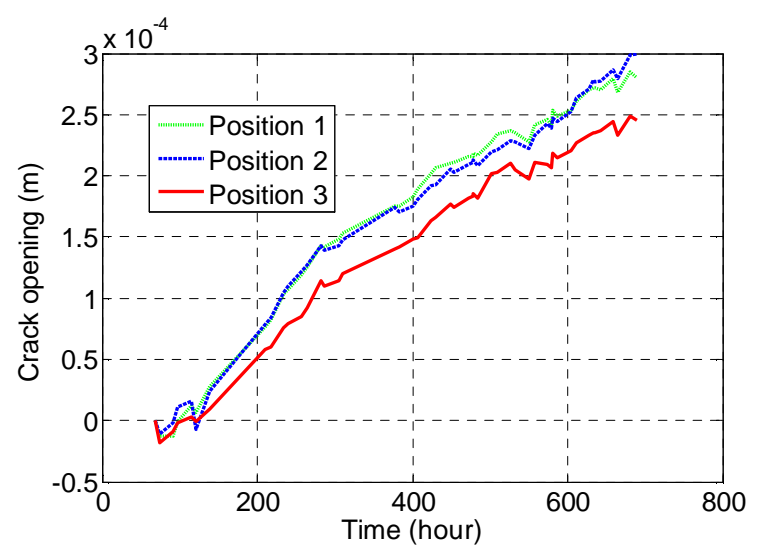

Fig. 7 Crack width versus time related to positions $1-3$

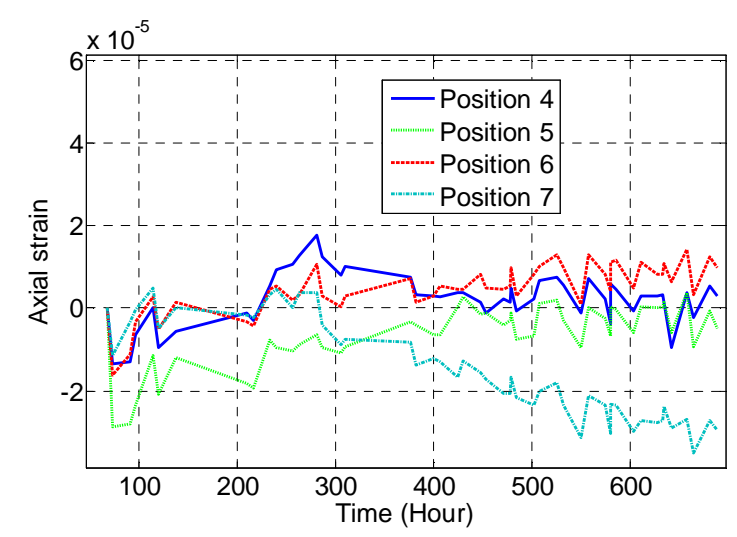

Fig. 8 Strain versus time related to positions $4-7$

values correspond to compressive strains.

Due to the swelling related to the corrosion products, cracks appear at the steel/concrete interface and propagate towards the concrete cover. Both crack pattern and crack mouth width were monitored. The experimental results related to the pins displacement are exposed in Figs. 7 and 8 .

In Fig. 7, the evolution of the crack width versus time is plotted. At the end of the accelerated corrosion test, the average crack width related to the main longitudinal crack is close to $300 \mu \mathrm{m}$. In Fig. 8, strain measurements related to positions 4 to 7 have been reported. The amplitude of the variations is very weak. From the experimental evidences, one can conclude that the swelling due to the corrosion products does not significantly affect the longitudinal direction. In other words, the plane strain hypothesis is fully justified and therefore, a 2D computation considering the cross section of the beam should be sufficient to model the problem.

The experimental study presented above is only focused on mechanical measurements, especially on crack mouth width of the main longitudinal crack. The authors have decided to monitor these quantities because they are the main parameters considered by civil engineers in charge of structural health monitoring. Moreover, no additional information is needed to show the 
efficiency and the relevancy of the post-treatment technique used in this study.

\section{Numerical identification of the local failure mechanisms}

\subsection{Continuous analysis}

The FE analysis lies in a two-dimensional model of the RC beam cross-section. Due to the high length of the RC sample (with respect to the width and the thickness), the plane strain state hypothesis has been considered. This assumption is consistent with experimental longitudinal strain measurements of the beam, as previously underlined. Concrete was meshed with 25,142 three-node triangular elements. This high number of elements contributes to a rather fine mesh and is suitable since an accurate damage pattern is expected. In the present study, due to some random materials characteristics introduced over the concrete domain, FE modelling does not take advantage of the specimen symmetry. Steel/concrete interface was meshed with zero-thickness elements. The growth of corrosion products is modelled by a specific constitutive law that has been developed for (Richard et al. 2010c). The corrosion growth is described by prescribing a radial displacement at the steel/concrete interface. Indeed, this strategy requires meshing explicitly the steel/concrete interface by means of zero-thickness finite elements. The value of the radial displacement prescribed is a function of time, which is itself a function of a macroscopic corrosion degree. One can point out that a linear relation between the macroscopic corrosion degree and the time is considered in the model that is often the case when dealing with accelerated corrosion tests. In accordance with the experimental conditions, the vertical displacements related to the bottom line have been assumed to be simply supported. In order to avoid unwanted rigid modes, the rightbottom point has been built-in.

An important step that must be carried out thoroughly is the material parameter identification. To characterize the mechanical properties of the concrete, standard destructive tests were carried out as previously mentioned. Measured values of the Young's modulus have both been taken into account in the constitutive model. During the compression test, the whole stress/strain curve was monitored. Wedge splitting tests were carried out to measure the tensile strength that has been input in the model. To take the heterogeneity of the concrete into account, the tensile strength has been considered as a random variable. Its mean value is equal to the experimental one and a coefficient of variation has been assumed equal to $15 \%$, according to the observed experimental deviation. The random field of tensile strength is shown in Fig. 9.

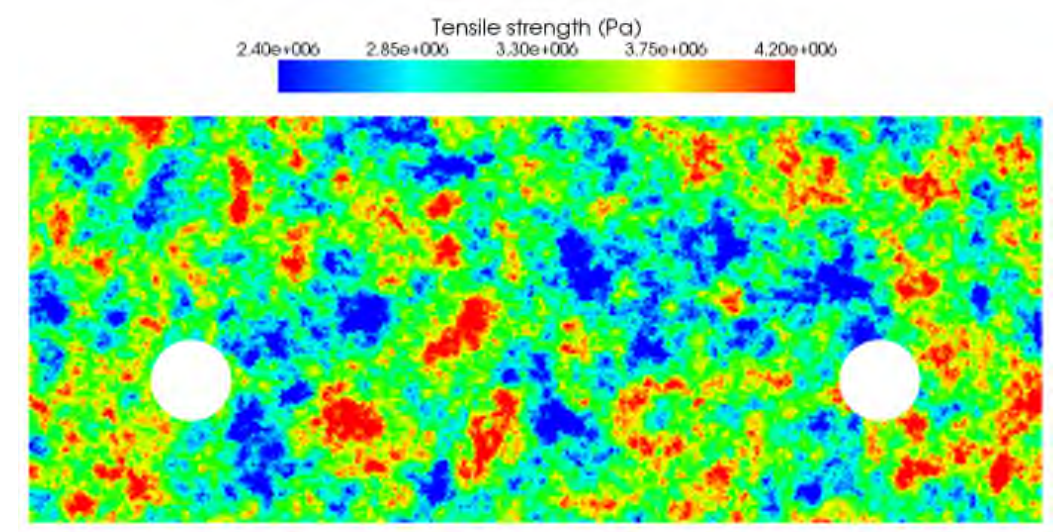

Fig. 9 Representation of the random field of the tensile strength over the finite element mesh 


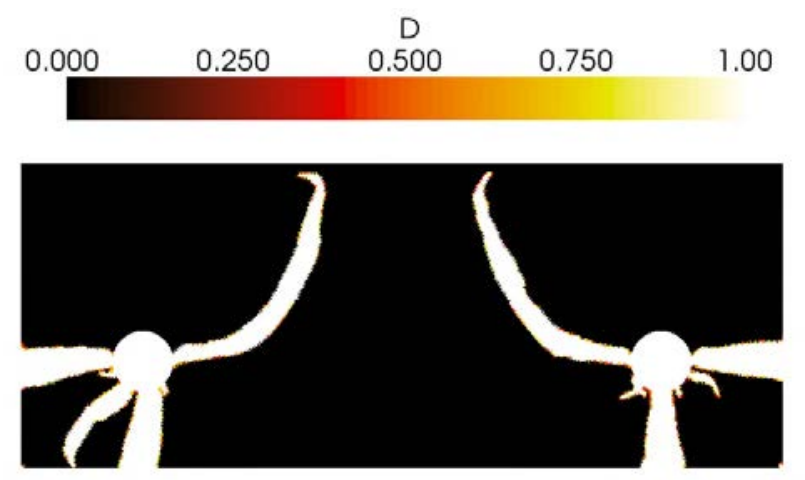

Fig. 10 Continuous damage pattern

A continuity of the tensile strength distribution must be ensured in order to avoid the presence of specific areas where strain will localize. Therefore, a correlation length equal to 3 times the maximum aggregate size in the concrete mixture has been considered in the Gaussian random field. It can be observed that weak zones and strong ones are represented. This is particularly important to describe properly not only the crack propagation but also the crack widths since the maximum aggregate size used is quite high $(20 \mathrm{~mm})$.

The continuum damage mechanics based model formulated to describe the mechanical behaviour of concrete can be turned to represent crack propagation. The authors would like to emphasize the fact that cracking is described in a continuous way and the displacement jump is not explicitly described. Therefore, the crack widths cannot be computed straightforwardly.

The results of the calculation are shown in Fig. 10. The isovalues of the scalar damage variable have been represented on the FE mesh used for the analysis. This damage pattern is only due to the swelling of corrosion products since no mechanical loading is considered. The dissymmetry between both damage patterns around the two steel rebars is due to the concrete tensile strength sampled over the FE mesh to take into account its heterogeneity (random tensile strength). This result helps defining the ROI to analyze by mean of the discrete approach.

\subsection{Identification of the $R O I$}

Since the apparent crack width is located at the bottom left corner of the RC specimen, only this area has been meshed by discrete elements. The ROI has been chosen regarding the measurements that have been carried out, leading to consider only the bottom left corner. It must be underlined that applying the DE method to the whole region does not make sense and would lead to an unnecessary computational cost. The selected ROI presented in Fig. 11 is a 7529particle mesh including 22587 degrees of freedom.

The boundary conditions lie in applying the continuous displacement field (coming from the finite element analysis presented in section 4.1) on the non-free boundaries of the discrete zone for all time steps. As this way, the corrosion growth could be reproduced.

\subsection{Discrete analysis}


The model elastic parameters are identified following the procedure given in (Woestyn et al.

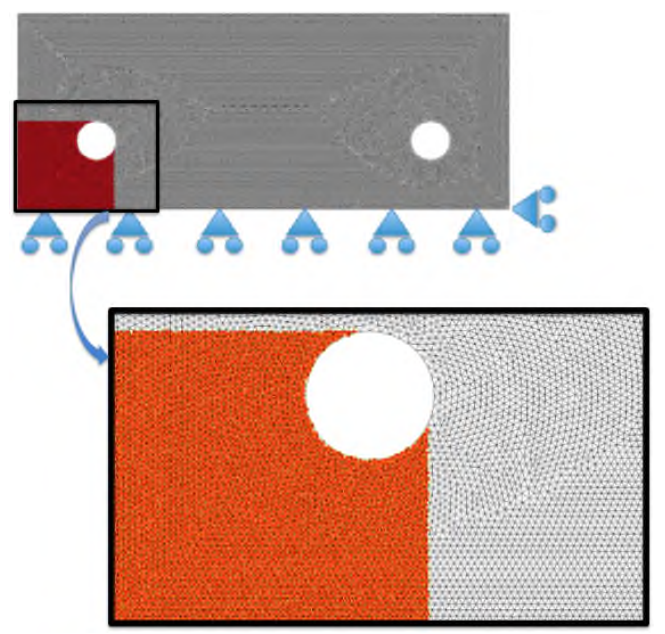

Fig. 11 Position of the ROI (in red), continuous boundary conditions and zoom in the ROI

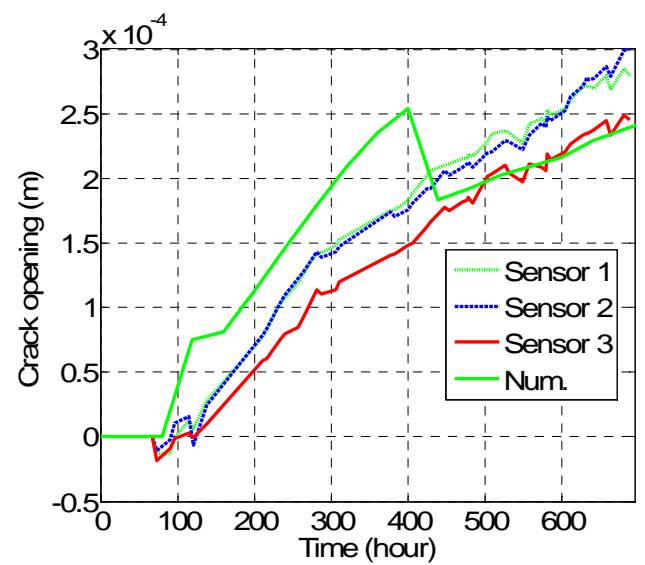

Fig. 12 Experimental and numerical crack width versus time curves

2006). First, the adimensional parameter $\alpha$ (beam moment of inertia normalized by the moment of inertia of an equivalent circular section) is identified in order to fit the Poisson's ratio then the elastic modulus of the beam is identified to fit the material Young's modulus. The corresponding values are $\alpha=0.83$ and $E_{b}=46 \mathrm{GPa}$. The nonlinear parameters are also identified in two steps. The first one allows identifying the beam strain threshold $\varepsilon_{i j}^{c r}$ with respect to the material tensile strength. The second step allows identifying the rotation threshold $\theta_{i j}^{c r}$ with respect to the material compressive strength. The corresponding values are $\varepsilon_{i j}^{c r}=1.210^{-4}$ and $\theta_{i j}^{c r}=28^{\circ}$ (Delaplace $e t$ al. 2007), (Delaplace 2009).

The evolution of the crack width (numerical and experimental values) with respect to the time is shown in Fig. 12.

The crack width is equal to zero until the crack becomes noticeable on the left side. Then, the 
width increases regularly. One can note the good agreement between the experimental value and

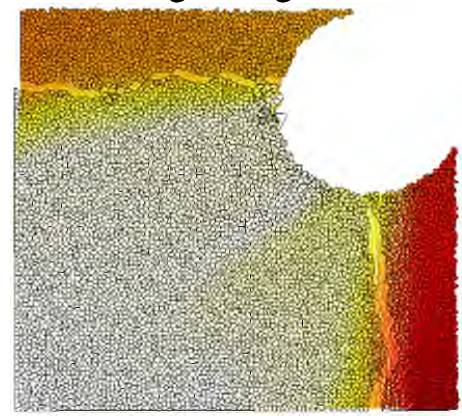

Fig. 13 Numerical discrete crack pattern

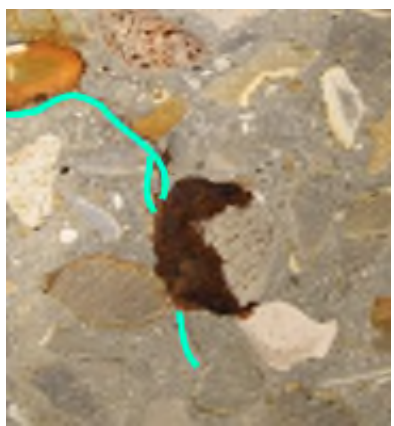

Fig. 14 Experimental crack pattern

the numerical one. In fact, the slope in terms of crack width has been captured. This effect is discussed in details in next section. The numerical crack pattern that has been computed from the discrete approach and the experimental one are shown in Figs. 13 and 14. One can notice that the two mean cracks are well captured.

More information about the crack width slope is provided in next section by analyzing the failure kinematics. Nevertheless, it can be concluded that the numerical approach is in accordance with the experimental measurements, showing its relevancy and its ability to describe satisfactorily such complex nonlinear phenomena.

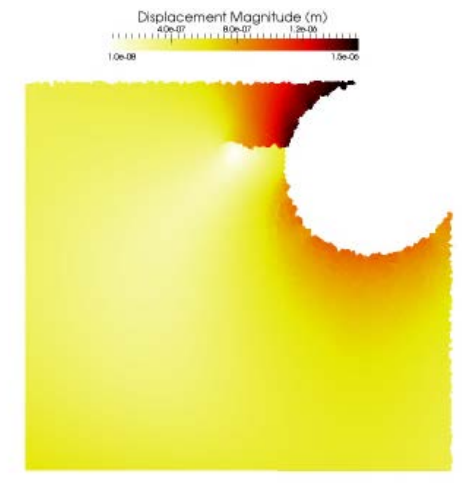

Fig. 15 Crack pattern for $\mathrm{t}=200 \mathrm{~h}$ 


\subsection{Discussion}

The cracking patterns obtained from the DE model for different time steps are shown in Figs. 15, 16 and 17. Since DE method can handle the management of displacement discontinuities, the cracking pattern can be observed by being focused on the displacement field.

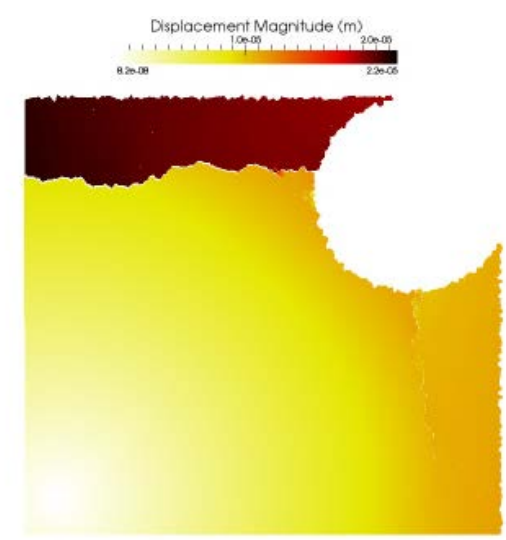

Fig. 16 Crack pattern for $\mathrm{t}=400 \mathrm{~h}$

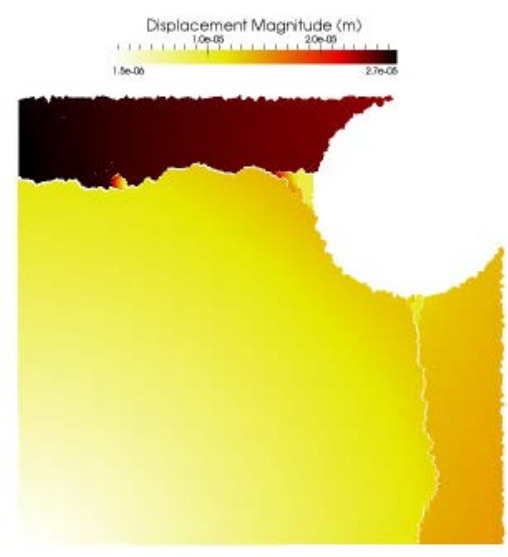

Fig. 17 Crack pattern for $t=600 h$

The propagation process can be split into three different steps. In the first step, a first crack starts from the steel rebar and propagates toward the left side. Before the first crack reaches the free surface of the left side, a second crack starts from rebar that is the signature of the second step. In the final step, the second crack keeps on propagating. A very interesting result related to the cracking process kinematics can be extracted from such analysis. In the first step, the first crack keeps on opening. In the second step, due to the fact that the first crack has already reached the free surface, the propagation of the second one induces a partial closure of the first one. This is probably the reason why the crack width/time curve shown in Fig. 12 exhibits a discontinuity. One 
can point out that this feature is observed not only in the experiment but also in the computation.

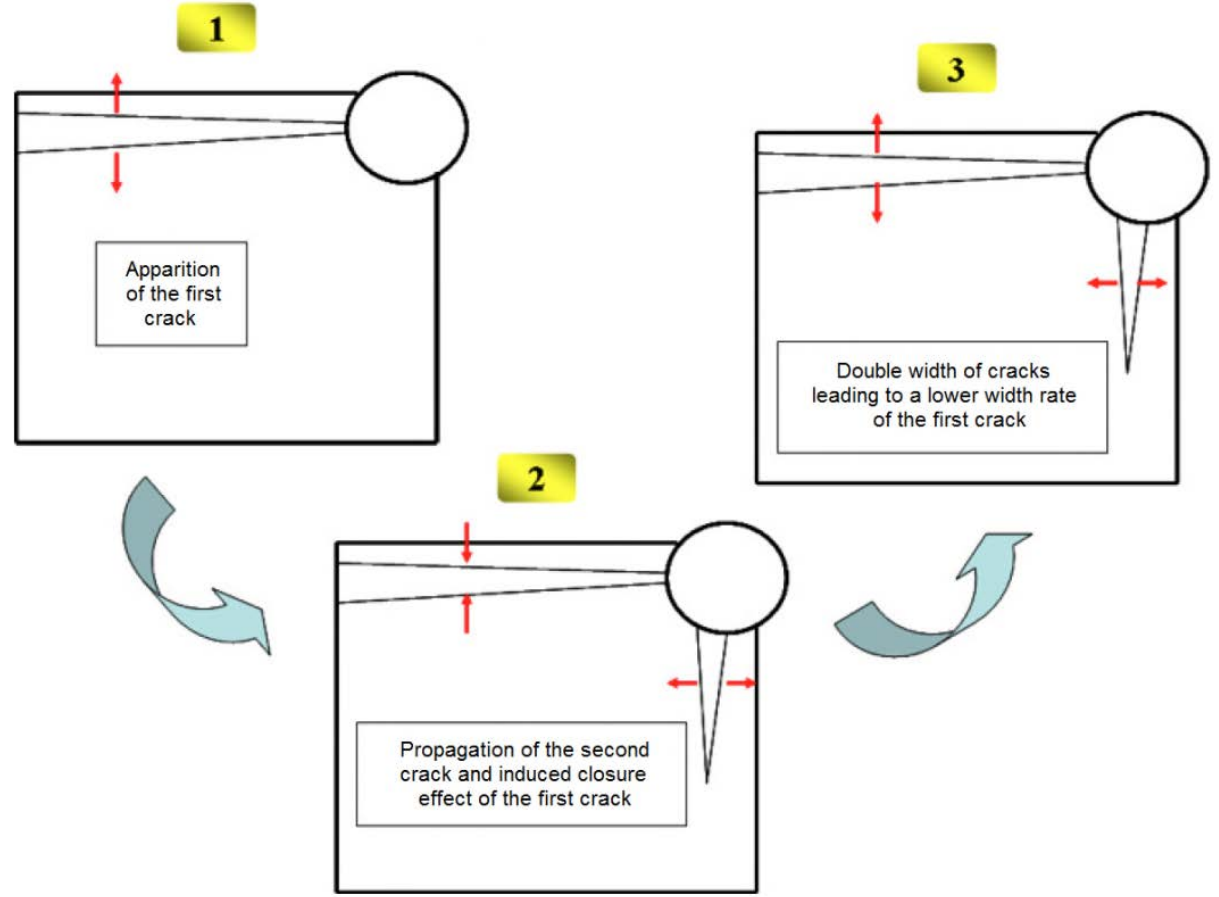

Fig. 18 Schematic description of the local failure mechanism

This phenomenon can be seen as a rigid body displacement of the concrete block delimited by both cracks. In the final step, the width of the two cracks interacts with each other, leading to a lower width rate. One could point out this complex failure kinematics thanks to the accurate numerical methodology that has been used in this study. A schematic representation of the failure kinematics is shown in Fig. 18. It is noticed that the propagation of the corrosion products through the opened cracks is not taken into account in the model. Such corrosion products can saturate the crack and block its closing.

\section{Conclusions}

This study has been carried out with the objective to show that advanced numerical techniques could be used to handle practical problems in the field of maintenance of RC structures, namely corrosion-induced cracking. To reach this objective, an accelerated corrosion test has been realized by the authors. The experiment is focused on corrosion-induced cracking, not only from a qualitative point of view but also from a quantitative one. A post-mortem analysis as well as a crack width measurement has been carried out.

These results have been used to feed the numerical analysis. In response to the main objective of that study, a recent numerical approach that combines FE and DE methods has been used. As it has been highlighted in this paper, this methodology allows capturing very local phenomena such as stresses redistributions and crack propagation in an accurate way. This technique can be seen as 
a post-treatment for structural health assessment. In other words, from continuous computations (that are largely used by civil engineers), local information such as crack features can be captured. This approach can be used with any satisfactory continuous model, without any modification of the computational software. From the numerical analysis exposed in this paper, one has observed that both qualitative and quantitative information are well described. Therefore, the post-treatment technique used in this study helps to highlight local failure mechanisms due to corrosion-induced cracking. Indeed, the global failure kinematics can be analyzed and discussed, leading to the identification of the effect of each crack.

The results reported in this paper contribute to identify the local failure mechanism due to corrosion-induced cracking in an accurate way. Further work aiming at linking crack features at the surface of the concrete cover with a local corrosion state is ongoing. The authors deeply think that the numerical tool used in this study can help to carry out this work and that critical threshold in terms of crack widths allowing to better control the effect of corrosion could be provided to civil engineers in charge of in-site diagnosis and maintenance.

\section{Acknowledgments}

The investigations and results reported herein were supported by the National Research Agency (France) under the APPLET research program (grant ANR-06-RGCU-001-01).

\section{References}

Adelaide, L., Richard, B., Ragueneau, F. and Cremona, C. (2010), "Thermodynamical admissibility of a set of constitutive equations coupling elasticity, isotropic damage and internal sliding", Compt. rendus méca., 338(3), 158-163.

AFNOR (2001), Testing hardened concrete. Part 6: Tensile splitting strength of test specimens, NF EN 12390-6.

AFNOR (2003), Testing hardened concrete. Part 3: Compressive strength of test specimens, NF EN 123903.

Andrade, C., Alonso, C. and Molina, F.J. (1993), "Cover cracking as a function of bar corrosion: Part IExperimental test”, Mater. Struct., 26(8), 453-464.

Armstrong, P. and Frederick, C. (1966), "A mathematical representation of the multiaxial bauschinger effect (cegb report rd/b/n/731)", Berkeley Laboratories, R\&D Department, CA.

Belytschko, T. and Black, T. (1999), "Elastic crack growth in finite elements with minimal remeshing", Int. J. Numer. Method. Eng., 45(5), 601-620.

Bentur, A. and Berke, N. (1998), "Steel corrosion in concrete, fundamentals and civil engineering practice", SPON.

Bertolini, L., Elsener, B., Pedeferri, P. and Polder, R. (2004), "Corrosion of steel in concrete, Prevention, diagnosis and repair", Vch Verlagsgesellschaft Mbh.

Broomfield, J.P. (1997), “Corrosion of steel in concrete, understanding, investigation and repair", E\&FN SPON, London.

Caré, S. and Raharinaivo, A. (2007), "Influence of impressed current on the initiation of damage in reinforced mortar due to corrosion of embedded steel", Cement Concrete Res., 37(12), 1598-1612.

Caré, S., Nguyen, Q.T., Beddiar, K. and Berthaud, Y. (2010), "Times to cracking in reinforced mortar beams subjected to accelerated corrosion tests", Mater. Struct., 43(1-2), 107-124.

Delaplace, A. (2009), "Tensile damage response from discrete element virtual testing", Geomech. Geoeng., 
4(1), 79-89.

Delaplace, A. and Desmorat, R. (2007), "Discrete 3D model as complimentary numerical testing for anisotropic damage", Int. J. Fract., 148(2), 115-128.

Delaplace, A. and Ibrahimbegovic, A. (2006), "Performance of time-stepping schemes for discrete models in fracture dynamic analysis”, Int. J. Numer. Method. Eng., 65(9), 1527-1544.

Dolbow, J.O.H.N. and Belytschko, T. (1999), "A finite element method for crack growth without remeshing", Int. J. Numer. Method. Eng., 46(1), 131-150.

Dragon, A. and Mroz, Z. (1979), "A continuum model for plastic-brittle behaviour of rock and concrete", Int. J. Eng. Sci., 17(2), 121-137.

Frémond, M. and Nedjar, B. (1995), "Damage in concrete: the unilateral phenomenon", Nucl. Eng. Des., 156(1), 323-335.

Grassl, P. and Jirásek, M. (2006), "Damage-plastic model for concrete failure”, Int. J. Solid. Struct., 43(22), 7166-7196.

Jason, L., Huerta, A., Pijaudier-Cabot, G. and Ghavamian, S. (2006), "An elastic plastic damage formulation for concrete: Application to elementary tests and comparison with an isotropic damage model", Comput. Method. Appl. Mech. Eng., 195(52), 7077-7092.

Jirasek, M. and Zimmermann, T. (1998), "Rotating crack model with transition to scalar damage", J. Eng. Mech., 124(3), 277-284.

Jirasek, M. and Zimmermann, T. (2001), "Embedded crack model: I. Basic formulation”, Int. J. Numer. Method. Eng., 50(6), 1269-1290.

Jirasek, M. and Zimmermann, T. (2001b), "Embedded crack model. Part ii: Combination with smeared cracks", Int. J. Numer. Method. Eng., 50(6), 1291-1305.

La Borderie, C., Mazars, J. and Pijaudier-Cabot, G. (1992), "Response of plain and reinforced concrete structures under cyclic loadings", Special Pub., 134, 147-172.

Lemaître, J., Chaboche, J.L. and Germain, P. (1985), Mécanique des matériaux solides, Dunod.

Mattews, S., Sarkkinen, M. and Morlidge, J. (2007), "Conrepnet: Performance-based approach to the remediation of reinforced concrete structures: Achieving durable repaired concrete structures", J. Build. Appraisal, 3(1), 6-20.

Mazars, J. (1989), "Continuum damage theory: application to concrete", J. Eng. Mech., 115(2), 345-365.

Mazars, J., Berthaud, Y. and Ramtani, S. (1990), "The unilateral behaviour of damaged concrete", Eng. Fract. Mech., 35(4), 629-635.

Mehta, P., Monteiro, P. and Ebrary, I. (2006), Concrete microstructure, properties and materials, McGrawHill New York.

Moukarzel, C. and Herrmann, H.J. (1992), “A vectorizable random lattice”, J. Stat. Phys., 68(5-6), 911-923.

Nguyen, Q., Caré, S., Millard, A. and Berthaud, Y. (2007), "Analyse de la fissuration du béton armé en corrosion accélérée”, Comptes Rendus de l'Académie des Sciences: Mécanique, 335(2), 99-104.

Oliver, J. (1996), "Modelling strong discontinuities in solid mechanics via strain softening constitutive equations. Part 1: Fundamentals", Int. J. Numer. Method. Eng., 39(21), 3575-3600.

Oliver-Leblond, C., Delaplace, A., Ragueneau, F. and Richard, B. (2013), "Non-intrusive global/local analysis for the study of fine cracking”, Int. J. Numer. Anal. Method. Geomech., 37(8), 973-992.

Pensée, V., Kondo, D. and Dormieux, L. (2002), "Micromechanical analysis of anisotropic damage in brittle materials", J. Eng. Mech., 128(8), 889-897.

Pijaudier-Cabot, G. and Bazant, Z.P. (1987), "Nonlocal damage theory", J. Eng. Mech., 113(10), 1512-1533.

Ragueneau, F., Dominguez, N. and Ibrahimbegovic, A. (2006), "Thermodynamic based interface model for cohesive brittle materials: Application to bond slip in RC structures", Comput. Method. Appl. Mech. Eng., 195(52), 7249-7263.

Ragueneau, F., La Borderie, C. and Mazars, J. (2000), "Damage model for concrete-like materials coupling cracking and friction, contribution towards structural damping: rst uniaxial application", Mech. Cohes. Frict. Mater., 5, 607625.

Richard, B., Delaplace, A., Cremona, C. and Ragueneau, F. (2010), "Combining finite/discrete element models: a post-processing tool for fine cracks in concrete structures", Fract. Mech. Concrete Concrete 
Struct.

Richard, B., Quiertant, M., Bouteiller, V., Adelaide, L., Tailhan, J.L. and Cremona, C. (2012), "Influence of accelerated corrosion on the reinforced cover concrete cracking behavior: experimental and numerical study”, Eur. J. Envir. Civil Eng., 16(3-4), 450-459.

Richard, B., Ragueneau, F., Cremona, C. and Adelaide, L. (2010b), "Isotropic continuum damage mechanics for concrete under cyclic loading: stiffness recovery, inelastic strains and frictional sliding", Eng. Fract. Mech., 77(8) 1203-1223.

Richard, B., Ragueneau, F., Cremona, C., Adelaide, L. and Tailhan, J.L. (2010), "A three-dimensional steel/concrete interface model including corrosion effects", Eng. Fract. Mech., 77(6), 951-973.

Rots, J. (1991), "Smeared and discrete representations of localized fracture", Int. J. Fract., 51, 45-59.

Schlangen, E. and Garbozci, E.J. (1997), "Fracture simulations of concrete using lattice models: Computational aspects”, Eng. Fract. Mech., 57, 319-332.

Tilly, G. and Jacobs, J. (2007), "Concrete repairs, Performance in service and current practice", CONREPNET, IHS BRE press.

Van Mier, J.G.M., Van Vliet, M.R.A. and Wang, T.K. (2002), "Fracture mechanism in particle composites: statistical aspects in lattice type analysis", Mech. Mater., 34(11), 705-724.

Woestyn, S., Delaplace, A. and Koechlin, P. (2006), "Analysis of the dynamical failure of concrete by mean of a discrete model", Revue Européenne de Génie Civil, 10, 1281-1308. 